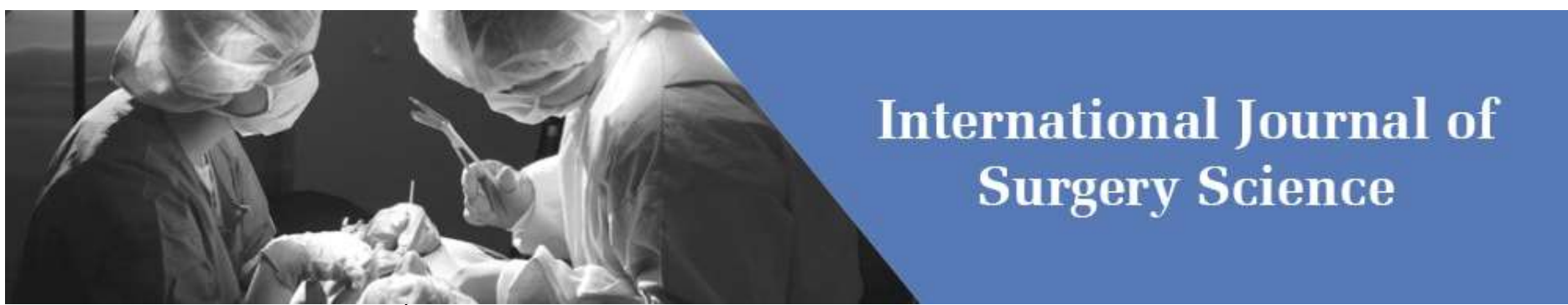

E-ISSN: 2616-3470

P-ISSN: 2616-3462

(C) Surgery Science

www.surgeryscience.com

2021; 5(2): 155-158

Received: 26-02-2021

Accepted: 29-03-2021

Surya Rao Rao Venkata Mahipathy Professor \& Head, Department of Plastic \& Reconstructive Surgery,

Saveetha Medical College \&

Hospital, Thandalam,

Kanchipuram, Tamil Nadu, India

\section{Alagar Raja Durairaj}

Professor \& Head, Department of

Plastic \& Reconstructive Surgery,

Saveetha Medical College \&

Hospital, Thandalam,

Kanchipuram, Tamil Nadu, India

Narayanamurthy Sundaramurthy Professor \& Head, Department of Plastic \& Reconstructive Surgery, Saveetha Medical College \&

Hospital, Thandalam,

Kanchipuram, Tamil Nadu, India

Anand Prasath Jayachandiran

Professor \& Head, Department of

Plastic \& Reconstructive Surgery, Saveetha Medical College \&

Hospital, Thandalam,

Kanchipuram, Tamil Nadu, India

Suresh Rajendran

Professor \& Head, Department of Plastic \& Reconstructive Surgery,

Saveetha Medical College \&

Hospital, Thandalam,

Kanchipuram, Tamil Nadu, India

Corresponding Author:

Surya Rao Rao Venkata Mahipathy

Professor \& Head, Department of

Plastic \& Reconstructive Surgery,

Saveetha Medical College \&

Hospital, Thandalam,

Kanchipuram, Tamil Nadu, India

\title{
Squamous cell carcinoma of the temporal region resurfaced with a transposition flap
}

\section{Surya Rao Rao Venkata Mahipathy, Alagar Raja Durairaj, Narayanamurthy Sundaramurthy, Anand Prasath Jayachandiran and Suresh Rajendran}

DOI: https://doi.org/10.33545/surgery.2021.v5.i2c.681

\section{Abstract}

Squamous cell carcinoma of the head and neck is common in all parts of the world. There are many pathologic subtypes which differ in histology and prognosis. Large tumors, deeper invasion, perineural involvement, recurrence and immunosuppression are associated with poor prognosis. The mainstay of treatment is surgery with adjuvant radiation therapy as needed for aggressive tumor. The use of Moh's micrographic surgery has become increasingly useful and has shown high success rates. Here, we present a case of squamous cell carcinoma of the forehead managed with surgical excision and resurfaced with a transposition flap cover.

Keywords: Squamous cell carcinoma, temporal region, histology and prognosis

\section{Introduction}

Nonmelanoma skin cancer is the most common type of cancer. Squamous cell carcinoma (SCC) is the second most common skin malignancy in the US after basal cell carcinoma (BCC). The annual incidence of SCC is from 200,000 to 300,000 per year and constitutes $20 \%$ of nonmelanoma skin cancers ${ }^{[1]}$. Sun exposed areas are at risk for development of disease with the head and neck having the highest incidence ${ }^{[2]}$. This could be related to increased sun exposure due to alterations in style of clothing, ozone depletion, and increased length of life [3-5]. Increased incidence is found among Caucasian populations where the majority of patients are men with an average age of $66^{[2,5]}$.

\section{Case Report}

70 year old elderly gentleman presented to us with an ulcer of the right side of forehead since 5 months. It was insidious in onset and had gradually progressed to the present size. There was no history of pain, trauma or fever. On examination, an ulceroproliferative growth of size $4 \mathrm{x} 3 \mathrm{~cm}$ over the right temporal region was present. The ulcer had raised and everted margins with unhealthy tissue in the base and not fixed to the underlying structures. There was $1 \mathrm{~mm}$ induration all around the ulcer. (Fig. 1,2) There was no regional palpable lymphadenopathy. A provisional diagnosis of squamous cell carcinoma was made. We planned for wide local excision with flap cover. Under IV sedation and local anaesthetic infiltration, wide local excision of the lesion was done with a $2 \mathrm{~cm}$ margin of clearance and sent for histopathological evaluation which confirmed as a well differentiated squamous cell carcinoma with all margins free of tumour. The defect was resurfaced with a local transposition flap and the secondary defect was covered with a split skin graft harvested from the left thigh, meshed and anchored with 3-0 nylon sutures tie-over bolster dressing. Haemostasis was secured and inset was given with 4-0 nylon sutures over Segmuller drains. (Fig. 3, 4, 5, 6) Post-operative was uneventful. 


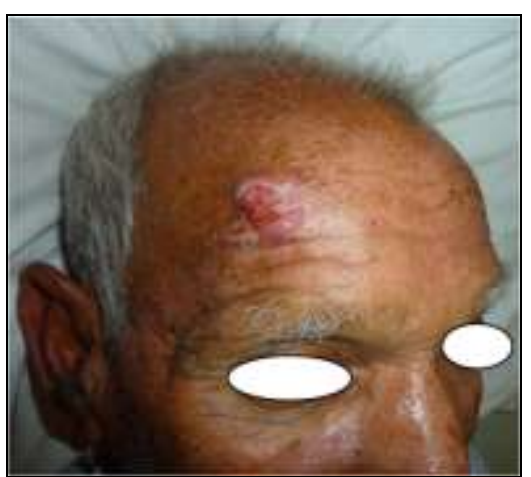

Fig 1: Clinical picture of the lesion

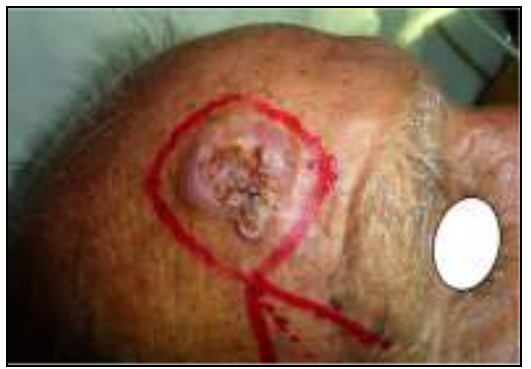

Fig 2: Marking of excision borders

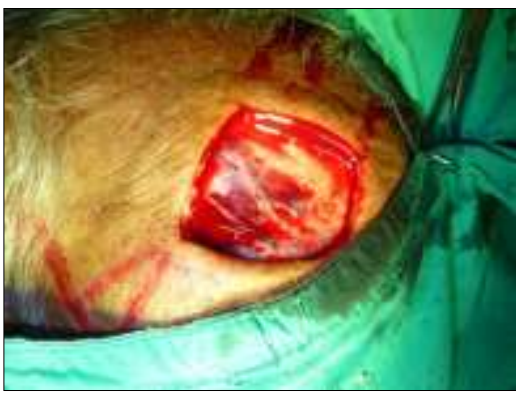

Fig 3: Defect after wide local excision

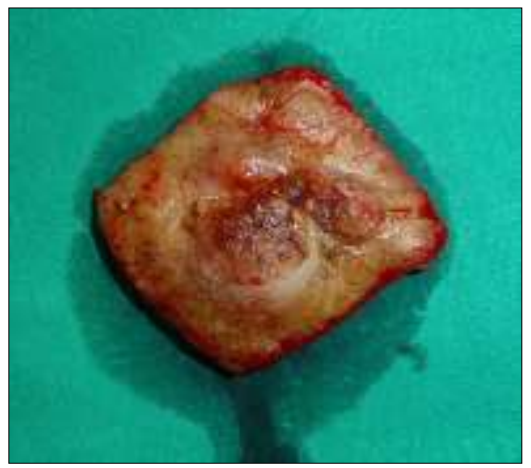

Fig 4: Specimen after excision

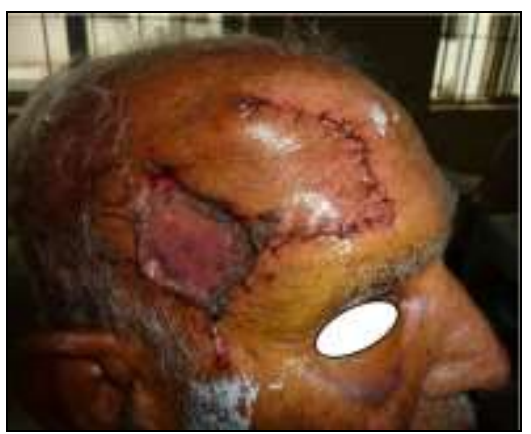

Fig 5: Early post-operative picture

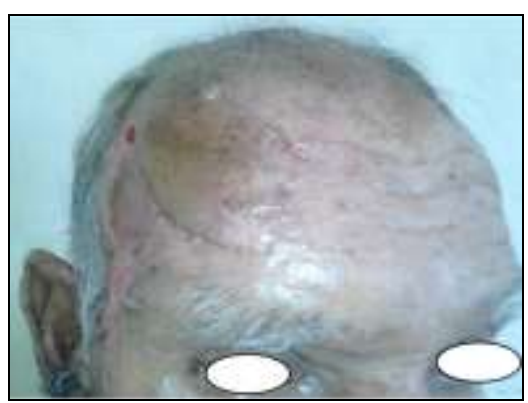

Fig 6: 3 months post-operative picture

\section{Discussion}

The most significant contribution to $\mathrm{SCC}$ is from ultraviolet radiation exposure. UV-B light $(200-320 \mathrm{~nm})$ is more carcinogenic than UV-A light (320-400 nm), although both can lead to malignancy ${ }^{[6]}$. The tumor-suppressor gene $\mathrm{p} 53$ has been described as a cause of this tumour. UV radiation can alter gene activity in keratinocytes, allowing genetically altered cells to avoid apoptosis ${ }^{[7,8]}$. It acts as an immunosuppressant and further deranges the normal defense against malignancy ${ }^{[9]}$. Defects in DNA repair mechanism in congenital diseases like xeroderma pigmentosum and oculocutaneous albinism, which are autosomal recessive have an increased incidences of skin malignancy ${ }^{[5]}$. Xeroderma pigmentosum carries a 2000-fold increased risk for SCC ${ }^{[10]}$. Individuals with human immunodeficiency virus are at high risk for developing aggressive SCC, with an increased risk of recurrence and metastasis [11]. Chronic inflammation, scars and wounds, chemical exposures from tobacco, arsenic, and coal-tar products are a potential source of SCC ${ }^{[4,5]}$. Ionizing radiation from occupational or therapeutic exposure can also lead to SCC in a cumulative dose-dependent fashion ${ }^{[4,5]}$. SCC originates from keratinocytes in the spinous layer of the epidermis. The most common form, the conventional type, has atypical keratinocytes invading the dermis, mitotic figures, hyperchromism, and pleomorphic nuclei. Keratin pearl formation and intercellular bridging is also common. SCC can be classified into well, moderately, and poorly differentiated forms ${ }^{[12]}$. The spindle cell variant is uncommon and occurs in UV damaged areas [13]. These tumors appear as ulcerated nodules or exophytic lesions and have a tendency toward perineural spread [12, 13]. Furthermore, the spindle cell variant has a lack of differentiation and can behave aggressively with immunohistochemistry showing positivity for vimentin, cytokeratin, and epithelial membrane antigen ${ }^{[14]}$. The verrucous variant of SCC is a rare, low-grade disease presenting as a slowly enlarging, fungating lesion [13]. Desmoplastic SCC is an aggressive variant characterized by an invasive clinical course and poor prognosis with 10 times the risk of local recurrence and 6 times the risk of metastasis compared to other tumors ${ }^{[15]}$. In the head and neck, SCC most commonly involves the ear, frontotemporal region, and cheek ${ }^{[16]}$. Lesions on the cheek, pinna, temple, forehead, anterior scalp, and postauricular area tend to metastasize to the parotid basin and level II lymph nodes ${ }^{[16,17]}$. Tumors from the posterior scalp are more likely to travel to level $\mathrm{V}$ while more anterior parts of the face often bypass the parotid and involve levels I and III ${ }^{[16]}$. Diagnosis of SCC requires a head and neck physical examination. In areas that are close to vital structures or may impede cosmesis, incisional or punch biopsies may be taken. These biopsies should include the dermis and allow the presence of malignancy to be confirmed. For smaller lesions away from critical areas, an excisional biopsy of the area allows for a diagnostic and potentially therapeutic procedure. CT 
scanning may be helpful in determining whether there is bone involvement, while magnetic resonance imaging is used for assessing nerve and probable dural spread. The mainstay of treatment for SCC is surgical resection. Chemotherapy agents like 5-Fluorouracil for SCC is not recommended or widely utilized as a treatment for cancer in cases of extracapsular extension or in residual neck disease ${ }^{[18]}$. Photodynamic therapy has been used as first line treatment for actinic keratosis and Bowen's disease as first line therapy but there is no evidence to support its use for invasive SCC ${ }^{[19]}$. Electrodesiccation and curettage is reserved for small, superficial tumors in noncosmetically important areas ${ }^{[20]}$. Cryosurgery also can be used for low-risk, superficial disease and should not be used for highrisk tumors as it has poor cosmetic outcome compared to surgical excision [20-22]. A major disadvantage for both cryosurgery and electrodesiccation and curettage is the lack of tissue for margin analysis during resection. The use of primary radiotherapy in patients with SCC depends on multiple factors including cosmesis, function, age, medical morbidity, and patient desire ${ }^{[23,24]}$. In older patients with major cosmetic and functional disturbance with surgery and reconstruction, radiotherapy can be an attractive option as well as in patients with unresectable disease. Surgical resection with pathological monitoring remains the primary method of treatment for SCC of the head and neck. Appropriate surgical margins for SCC are $4 \mathrm{~mm}$ for low-risk lesions and $6 \mathrm{~mm}$ is suggested for higher-risk lesions $[25,26]$. Surgical resection using Mohs micrographic surgery provides a high cure rate with an emphasis on tissue conservation ${ }^{[2]}$. Treatment of the lymph node basins draining SCC primary sites is important in high-risk, aggressive tumors. Various tumor sites require different levels to be included in selective neck dissection. Fine needle aspiration of suspicious nodes can be helpful to determine the need for neck dissection [27]. To better assess lymph node involvement, lymphatic mapping with sentinel lymph node biopsy (SLNB) is being done $[28,29]$. The post excisional defect should be covered with a robust and vascular tissue, hence, flaps are the method of choice. In our case, we have used a regular rectangular transposition flap to resurface the defect. A transposition flap is a random pattern flap that borrows skin laxity from an adjacent area in order to fill a defect in an area with little or no skin laxity and in the process, redistributes and redirects tension, assisting in closure of defects. In its transport, the flap is lifted, or "transposed" from a donor site over a segment of intervening tissue, to the recipient site. The flap is tethered to a pedicle so rotation should be as much to pull on its vascular pedicle. As transposition flaps are local flaps, they generally offer a good color and textural match. The final scars are geometric broken lines that may be less noticeable than long linear closures. The most common transposition flaps include rectangular flaps, rhombic flaps (and their variations), bilobed flaps, and banner flaps such as the nasolabial flap. Knowledge of the tissue dynamics and final scar lines are required during the planning and execution of these flaps.

\section{Conclusion}

Treatment of squamous cell carcinoma is a challenge to the treating surgeon. Surgical resection remains the treatment of choice and MMS is especially useful in high-risk patients or in functional and cosmetic areas. Aggressive tumors metastasizing to the neck requires consideration of multimodal therapy with surgery and radiation. Close surveillance, especially within the first two years after treatment, is recommended. Continued research is necessary to assess the utility of nonsurgical modalities of treatment of these tumours.

\section{References}

1. American Cancer Society 2010. http://www.cancer.org/.

2. Leibovitch I, Huilgol SC, Selva D, Hill D, Richards S, Paver R. Cutaneous squamous cell carcinoma treated with Mohs micrographic surgery in Australia I. Experience over 10 years. Journal of the American Academy of Dermatology 2005;53(2):253-260.

3. Veness MJ, Porceddu CE, Palme, Morgan GJ. Cutaneous head and neck squamous cell carcinoma metastatic to parotid and cervical lymph nodes. Head \& Neck 2007;29(7):621-631.

4. Diepgen TL, Mahler V. The epidemiology of skin cancer. British Journal of Dermatology, Supplement, supplement 2002;146(61):1-6.

5. Johnson TM, Rowe DE, Nelson BR, Swanson NA. Squamous cell carcinoma of the skin (excluding lip and oral mucosa). Journal of the American Academy of Dermatology 1992;26(3):467-484.

6. Kwa RE, Campana K, Moy RL. Biology of cutaneous squamous cell carcinoma. Journal of the American Academy of Dermatology 1992;26(1):1-26.

7. Hussein MR. Ultraviolet radiation and skin cancer: molecular mechanisms. Journal of Cutaneous Pathology 2005;32(3):191-205.

8. Ziegler A, Jonason AS, Leffell DJ et al. Sunburn and p53 in the onset of skin cancer. Nature 1994;372(6508):773-776.

9. Marks R. Squamous cell carcinoma. The Lancet 1996;347(9003):735-738.

10. Lohmann CM, Solomon AR. Clinicopathologic variants of cutaneous squamous cell carcinoma. Advances in Anatomic Pathology 2001;8(1):27-36.

11. Nguyen $P$, Vin-Christian $K$, Ming ME, Berger $T$. Aggressive squamous cell carcinomas in persons infected with the human immunodeficiency virus. Archives of Dermatology 2002;138(6):758-763.

12. Rudolph R, Zelac DE. Squamous cell carcinoma of the skin. Plastic and Reconstructive Surgery 2004;114(6):82e-94e.

13. Cassarino DS, DeRienzo DP, Barr RJ. Cutaneous squamous cell carcinoma: a comprehensive clinicopathologic classification: part one. Journal of Cutaneous Pathology 2006;33(3):191-206.

14. Smith KJ, Skelton HG, Morgan AM, Barrett TL, Lupton GP. Spindle cell neoplasms coexpressing cytokeratin and vimentin (metaplastic squamous cell carcinoma). Journal of Cutaneous Pathology 1992;19(4):286-293.

15. Breuninger H, Schaumburg-Lever G, Holzschuh J, Horny HP. Desmoplastic squamous cell carcinoma of skin and vermilion surface. A highly malignant subtype of skin cancer. Cancer 1997;79(5):915-919.

16. Vauterin TJ, Veness MJ, Morgan GJ, Poulsen MG, O'Brien CJ. Patterns of lymph node spread of cutaneous squamous cell carcinoma of the head and neck. Head \& Neck 2006;28(9):785-791.

17. O'Brien CJ. The parotid gland as a metastatic basin for cutaneous cancer. Archives of Otolaryngology 2005;131(7):551-555.

18. Chakrabarty, Geisse JK. Medical therapies for nonmelanoma skin cancer. Clinics in Dermatology 2004;22(3):183-188.

19. Braathen LR, Szeimies RM, Basset-Seguin $\mathrm{N}$ et al. Guidelines on the use of photodynamic therapy for nonmelanoma skin cancer: an international consensus. Journal of the American Academy of Dermatology 2007;56(1):125-143. 
20. Tull S, Nunley K, Sengelmann R. Nonsurgical treatment modalities for primary cutaneous malignancies. Dermatologic Surgery 2008;34(7):859-872.

21. Kuflik EG. Cryosurgery for skin cancer: 30 -year experience and cure rates. Dermatologic Surgery 2004;30(2):297-300.

22. Thissen MRTM, Nieman FHM, Ideler AHLB, Berretty PJM, Neumann HAM. Cosmetic results of cryosurgery versus surgical excision for primary uncomplicated basal cell carcinomas of the head and neck. Dermatologic Surgery 2000;26(8):759-764.

23. Mendenhall WM, Amdur RJ, Hinerman RW, Cognetta AB, Mendenhall NP. Radiotherapy for cutaneous squamous and basal cell carcinomas of the head and neck. Laryngoscope 2009;119(10):1994-1999.

24. Wang Y, Wells W, Waldron J. Indications and outcomes or radiation therapy for skin cancer of the head and neck. Clinics in Plastic Surgery 2009;36(3):335-344.

25. Thomas DJ, King AR, Peat BG. Excision margins for nonmelanotic skin cancer. Plastic and Reconstructive Surgery 2003;112(1):57-63.

26. Brodland DG, Zitelli JA. Surgical margins for excision of primary cutaneous squamous cell carcinoma. Journal of the American Academy of Dermatology 1992;27(2I):241-248.

27. National Comprehensive Cancer Network, Practice guidelines in oncology: basal and squamous cell skin cancer 2010. http://www.nccn.org/.

28. Michl C, Starz H, Bachter D, Balda BR. Sentinel lymphonodectomy in nonmelanoma skin malignancies. British Journal of Dermatology 2003;149(4):763-769.

29. Civantos FJ, Moffat FL, Goodwin WJ. Lymphatic mapping and sentinel lymphadenectomy for 106 head and neck lesions: contrasts between oral cavity and cutaneous malignancy. Laryngoscope 2006;116(3):(109):1-15. 